\title{
When climate and life finally devolve
}

\author{
It is traditional, as the year draws to a close, to try to predict what the future holds in store. It is less common to \\ ask, as Caldeira and Kasting do in this issue, "how much future?".
}

NEw calculations by Caldeira and Kasting on page 721 of this issue ${ }^{1}$ are about the destiny and ultimate demise of the biosphere - which is both dependent on and vulnerable to the evolution of our main-sequence star, the Sun. Their calculations provide the best estimate to date as to when the Earth's staple of abiotic and biotic processes that draw down atmospheric $\mathrm{CO}_{2}$ will be unable to offset a rising solar flux.

Predictions of the heat death of the biosphere have traditionally come from astronomers. But ten years ago, Earth scientists Lovelock and Whitfield showed that the biota would face a crisis $^{2}$ long before our planet is scorched as the Sun expands into a red-giant phase, in about 5 billion years. The crisis will be a scarcity of atmospheric $\mathrm{CO}_{2}$.

The trend over geological time has been for atmospheric levels of $\mathrm{CO}_{2}$ to decrease. (Current rising levels of $\mathrm{CO}_{2}$ from industrial and agricultural sources are, by comparison, just a blip on the geological landscape.) Driving this longterm steady decrease has been a combination of factors ${ }^{3}$ : the growth of continents, a declining geothermal heat flux, a sequence of evolutionary developments that increase the weatherability of the terrestrial surface, and an increasingly radiant Sun, all of which alter the dynamics of the geochemical system that balances the $\mathrm{CO}_{2}$ supplied by volcanism with its removal by global weathering. The ultimate consequences of this downward trend were spelled out by Lovelock and Whitfield: in just 100 million years, $\mathrm{CO}_{2}$ will drop below the minimum level necessary to support photosynthesis.

Caldeira and Kasting have recalculated the life span of the biosphere, using a more refined set of biological and physical inputs. These include a precise greenhouse function, increased photosynthetic efficiencies from $\mathrm{C} 4$ plants at reduced $\mathrm{CO}_{2}$ and allowance for a functional dependence of silicate weathering upon respiration from roots and soil organisms. With these modifications, Caldeira and Kasting have extended the tenure of the biosphere to ten times that predicted by Lovelock and Whitfield: we can breathe easy for about a billion more years. But finally, temperatures will soar to the upper limits tolerable to the most primitive microbes, and in another billion years again the Earth will undergo a final sterilization with the loss of the hydrogen from photolysed water to space.

Is an event so distant in time any cause for concern today? We certainly have more immediate problems during the coming century in trying to prevent our own selves from ravaging the biosphere. Nevertheless, Caldeira and Kasting's work raises issues that are hauntingly familiar: the role of $\mathrm{CO}_{2}$ as a greenhouse gas, a possible need for planetary engineering in maintaining the Earth's habitability (or rather its comfort for humans), and fundamental questions about the ultimate persistence of life and the pace of evolution.

None of the models, of course, allows for possible evolutionary innovations that might buy time for life as we know it (or do not know it). The current plenitude of life's biochemical cycling mechanisms - within cells, organisms and ecosystems - is impressive, and has probably evolved in response to times of scarcity ${ }^{4}$. For example, C4 plants (such as maize) concentrate $\mathrm{CO}_{2}$ in special bundle sheath cells, away from the sites of wasteful photorespiration; this innovation has evolved in the past 100 million years 5 , probably in response to falling levels of atmospheric $\mathrm{CO}_{2}$.

Future responses to scarcity could be technologically driven. In experiments for advanced life support, such as NASA's programme in closed ecological life-support systems, Biosphere 2 in Arizona, and the Russian Bios 3, carbon is assiduously cycled and $\mathrm{CO}_{2}$ is managed at levels well above that of the Earth. Such research is intended to give us the rudiments of understanding that could someday lead to the propagation of mini-biospheres across the Galaxy. The future ancestral Earth - dry, burnt, and dead - would then be fondly recalled in Heinleinian space songs as that mythic place of "cool green hills".

Our descendants or descendent species would not have to run from the devolution, however - they could fight. Shades in space or mirrors on the Earth that keep out a small fraction of the elevated future solar flux would be an option. Carbonates could be heated to release $\mathrm{CO}_{2}$, a technique proposed ${ }^{6}$ for the industrial stewardship of the carbon cycle on a 'terraformed' Mars ${ }^{7}$ to make up for the lack of the $\mathrm{CO}_{2}$-generating plate tectonics that we have on Earth.

More importantly, long before the solar-induced devolution of the biosphere comes to pass, the ability of Homo sapiens to persist will be tested not only by our own earthly transgressions, but by impacts from asteroids and comets. An impact that could destroy civilization and wipe out a quarter of the world's population is estimated to occur about every 500,000 years ${ }^{8}$.

Calculations of the life span of the biosphere bring to focus one additional matter of great philosophical import. If devolution-computing life forms evolved with just a billion years to spare, following a 3.5 billion year genealogy, we are presented with an intriguingly close temporal match between two essentially decoupled, developing systems. The time it takes for life and then technological intelligence to evolve is nearly identical, in the only case we know, to the window of opportunity afforded by an atmospheric resource, which is yoked, in part, to the luminosity history of a mainsequence star. That this window was open just long enough for our arrival will add impetus to the arguments used by proponents of the anthropic cosmological principle ${ }^{9}$, who find the Universe uncannily fine-tuned.

Overall, Caldeira and Kasting's study adds to our understanding of what Lovelock calls geophysiology and NASA calls Earth-system science: the Earth as an interconnected system of life, atmosphere, hydrosphere and lithosphere, a system whose organizational properties we are still discovering. While our concerns over habitability are often for the shorter term, in exploring the interplay of life and climate over geological timescales, we forge an appreciation for where knowledge must go.

Tyler Volk

Tyler Volk is in the Earth Systems Group, Department of Applied Science, 26 Stuyvesant Street, New York University, New York 10003, USA.

\footnotetext{
1. Caldeira, K. \& Kasting, J. F. Nature $360,721-723$ (1992)

2. Lovelock, J. E. \& Whitfield, M. Nature 296, 561-563 (1982).

3. Schwartzman, D. W. \& Volk, T. Palaeogeog. Palaeoclim Palaeoecol. 90, 357-371 (1991)

4. Barlow, C. \& Volk, T. BioSystems 23, 371-384 (1990)

5. Ehleringer, J. R. et al. Trends Ecol. Evol. 6, 95-99 (1991).

6. Fogg, M. J. Br. interplanet. Soc. 45, 315-329 (1992). 7. McKay, C. P. et al. Nature 352, 489-496 (1992).

8. Morrison, D. The Spaceguard Survey: Report of NASA International Near-Earth Object Detection Workshop (January 25, 1992).

9. Carter, B. Phil. Trans. R. Soc. A310, 347-363 (1983)
} 